\title{
Review Paper: Effectiveness of Dry Needling for the Management of Plantar Fasciitis: A Review Study
}

\author{
Saman Salehi $^{1}$ (D, Azadeh Shadmehr ${ }^{1 *}$ (D) Gholamreza Olyaei ${ }^{1}$ (D), Siamak Bashardoust Tajali ${ }^{1}$ (D), Seyed Mohsen Mir ${ }^{1}$ (D)
}

1. Department of Physiotherapy, School of Rehabilitation, Tehran University of Medical Sciences, Tehran, Iran.

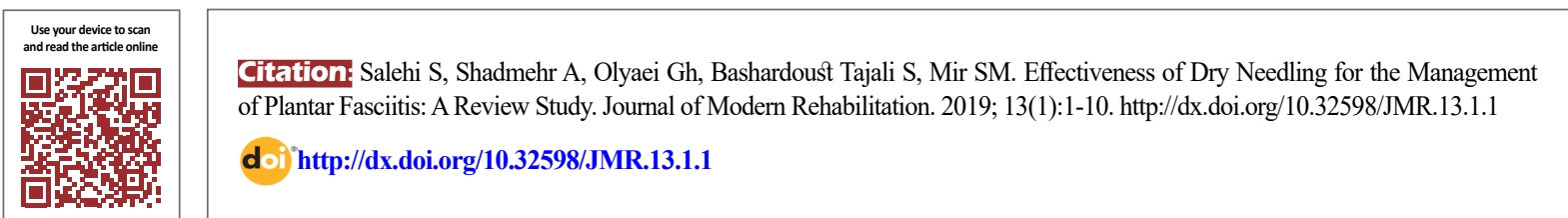

(c) (i) (5)

Article info:

Received: 10 Jul 2018

Accepted: 25 Nov 2018

Available Online: 01 Jan 2019

\section{Keywords:}

Dry needling, Trigger point, Myofascial trigger point, Plantar fasciitis, Heel pain, Plantar fascia, Heel spur

\begin{abstract}
Introduction: Plantar Fasciitis (PF) is an overuse syndrome as it develops over time. It is most frequently seen in both the non-athletic and athletic populations. PF is a multifactorial and self-limiting disorder that several factors are involved in its onset. Many well-established treatments are available for plantar heel pain. The purpose of this review is to determine the effectiveness of dry needling for the management of PF.

Materials and Methods: This article is a review study, in which we present the studies that compare dry needling with other treatments for the management of plantar heel pain. We included all of the studies on patients with plantar heel pain and plantar fasciitis that investigated the effects of dry needling. Finally, seven articles were included in this review. The study designs were randomized controlled, quasi-experimental, and case-control. The Physiotherapy Evidence-based Database (PED) scale was used to measure the methodological quality of the studies.
\end{abstract}

Results: The PEDro scoring of the articles ranged between 2.10-7.10. The results of this review show that dry needling may be useful in improving the pain of individuals with plantar heel pain and plantar fasciitis.

Conclusion: Further high-quality research studies are needed to determine the effectiveness of dry needling in the management of plantar heel pain. Because a variety of protocol treatments of dry needling were used in the studies, we cannot recommend dry needling schedule prescriptions for the management of individuals with plantar heel pain and plantar fasciitis.

\section{Introduction

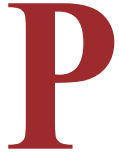 \\ lantar Fasciitis (PF) is an overuse syn- drome as it develops over time and a com- mon condition affecting the adult popula- tion [1-3]. PF affects approximately $10 \%$ of the world's general population $[4,5]$. It \\ is most frequently seen both in non-athletic and athletic}

communities [6-8]. This musculoskeletal disorder accounts for 3\% of all injuries associated with sports activities and $14 \%$ of all injuries in runners $[9,10]$. Although the word "fasciitis" assumes an inflammatory state, the evidence shows that PF is a degenerative disorder and should be appropriately classified as a "fasciosis" or "fasciopathy" [11-13]. PF is a degenerative syndrome of the plantar fascia resulting from frequent trauma on

\section{* Corresponding Author:}

Azadeh Shadmehr, PhD.

Address: Department of Physiotherapy, School of Rehabilitation, Tehran University of Medical Sciences, Tehran, Iran

Tel: +98 (937) 3123827

E-mail: salehisaman94@yahoo.com 
the calcaneus $[14,15]$. Over time, the repetitive trauma makes structural fatigue and weakening of the connective tissue, leading to pain and discomfort on the medial plantar side of the foot in heel area [15].

It is a clinical situation that presents as sharp pain and tenderness under the heel and pain worsening by weightbearing activities $[16,17]$. Individuals with PF may report the most severe pain in the heel while starting an activity or after a period of rest in the morning [17, 18]. Up to $20 \%$ of people with plantar fasciitis expand it bilaterally, which is more common in chronic state than acute state [19]. The onset of plantar fasciitis is insidious and may get worse over time and limit the performance of athletic activities, work-related duties, or even routine activities [20,21].

$\mathrm{PF}$ is a multifactorial and self-limiting disorder that several factors are involved in its onset [22]. Common risk factors usually reported in the literature include aging; high body mass index; anatomical problems such as pes planus, pes cavus foot types, excessive tibial torsion, or leg length discrepancy; tightness in gastrocnemius and soleus muscles; weakness of intrinsic foot muscles; prolonged standing and running activities; using improper shoe fit and wear; previous injury and running variables such as surface, speed, frequency and distance per week [20, 23-29].

A detailed patient's history and clinical examination can provide valuable information for a physical therapist for the diagnosis of PF. A clinical exam that includes pain in the first step, pain score more than 3 based on Visual Analog Scale (VAS) in side involvements, noticeable pain after prolonged rest and weight-bearing activities, pain on palpation of the proximal attachment of the plantar fascia, and decreased ankle dorsiflexion may indicate PF $[18,30]$. Tarsal tunnel syndrome, entrapment of the first branch of the lateral plantar nerve, radiculopathy in L4-L5, L5-S1, and stress fracture in calcaneus are differential diagnoses of PF.

In addition to clinical examination, diagnostic imaging is useful for the diagnosis of PF $[22,30]$. Ultrasound and MRI should be considered as the first- and second-line diagnostic imaging for the evaluation of PF [22]. Sonographic characteristics of plantar fasciitis include loss of fibrillar structure, increased thickness over $4 \mathrm{~mm}$, and decreased echogenicity $[26,31,32]$. MRI characteristics of plantar fasciitis include increased thickness, edema in the adjacent soft tissue, and bone marrow edema of the calcaneal attachment of the plantar fascia [33-35].

\section{Anatomy and function of the plantar fascia}

The plantar fascia is a strong flat band, lies superficial to the intrinsic plantar foot muscles $[36,37]$. It is a plantar aponeurosis that connects the heel bone to toes [38]. The plantar fascia originates from the medial tubercle of the calcaneus and inserts into the phalanges [38]. The plantar fascia contains three bands: Central, lateral, and medial [37, 38].

The thick central part covers the central muscle of the first layer, flexor digitorum brevis, and acts as a truss. The central band is proximally thick and distally slim. The central component is the thickest of the three. It arises from the medial tubercle of the calcaneus tubercle and expands distally, where it intersects into five sections that attach into the metatarsophalangeal joints. The lateral component is also proximally thick and distally thin. It expands from the lateral margin of the medial calcaneal tubercle, covers the plantar surface of the abductor digiti minimi muscle, and inserts to the fifth metatarsal joint capsule. The medial portion is thinner than the central and lateral bands. It arises from the middle of the central band, covers the plantar surface of the abductor hallucis muscle, and inserts to the first metatarsal joint capsule.

The plantar fascia has a fundamental role in the biomechanics of the foot. The plantar fascia is one of the major stabilizing structures of the longitudinal arch of the foot $[34,36]$. It supports the arches of foot, maintaining the medial longitudinal arch of the foot, sustains high tensions during weight-bearing, assists shock absorption during walking and weight-bearing activities [34, 36, 39].

The PF contains mostly type I collagen fibers that are arranged in the longitudinal direction in a proximal-distal direction, with a few transversal and vertical collagen fibers [38]. The mean thickness of plantar fascia was reported $4 \mathrm{~mm}$ in its central bundle, $2.3 \mathrm{~mm}$ in its lateral bundle, and $0.6 \mathrm{~mm}$ in its medial bundle. PF thickness is more in men than women [22, 40]. Based on the current evidence, a plantar fascia thickness of more than $4.0 \mathrm{~mm}$ on ultrasound imaging and MRI is consistent with PF $[22,40]$.

\section{Dry needling}

Various treatment approaches are used for the management of PF, including conservative treatment, orthotics, injection, and surgery [41]. The first-line management in the treatment of plantar fasciitis usually is conservative treatment and physical interventions [42]. Conservative 
treatment of PF often encompasses the use of dynamic and static mechanical devices, and exercise therapy includes stretching and strengthening exercises and manual therapies such as joint mobilization, manipulation, and massage and myofascial release [41-43]. The conservative treatment options for PF may be used singly or in combination.

Around $10 \%$ of individuals with PF cannot be rescued by physical and conservative treatment and may go on to have surgical treatment $[44,45]$. The recovery period of surgical treatment is long considered the last-line intervention, because of postoperative complications such as reflex sympathetic dystrophy and damage to the posterior tibial nerve. Despite many suggested therapies, enough evidence does not support the effectiveness of these interventions, and optimal treatment for PF has remained unclear.

Other alternative treatment options for relieving PF symptoms include laser therapy [46, 47], extracorporeal shockwave therapy [48], and dry needling [49-55]. Trigger point dry needling is an invasive option and has been widely used as an alternative treatment for PF [56]. It is an invasive treatment to alleviate pain through the use of an acupuncture needle [57, 58]. Myofascial trigger point dry needling is widely used for the treatment of a variety of myofascial pain syndromes $[57,59,60]$. Myofascial pain syndromes caused by existence one or more hyperirritable points in voluntary muscles $[61,62]$.

The exact mechanism of dry needling in treating myofascial pain syndromes is unclear. However, several studies have shown that dry needling can modify the biochemical environment surrounding a myofascial trigger point $[63,64]$. It has been proposed that dry needling hyperstimulates the pain-production area and thereby decreases the local sensory signals [65]. Another hypothesis suggests that dry needling fires inhibitory interneurons, preventing normal pain conduction to the sensory cortex [66]. The purpose of this review is to determine the effectiveness of dry needling as a treatment for management PF.

\section{Materials and Methods}

The review was conducted using a research question framed by PICO methodology. The PICO components were as follows: Population (individuals with plantar heel pain and plantar fasciitis), Intervention (dry needling), Comparison (standard intervention or control or placebo), and Outcome (pain, self-report, ultrasonog- raphy findings, foot function). We included the papers published in full text and the English language.

\section{Search strategy}

This article is a review study, and we present the articles that compared dry needling with other treatments for the management of plantar heel pain. We included all of the studies on patients with plantar heel pain and PF that investigated the effects of dry needling to treat them. These articles were randomized controlled, quasiexperimental trials, and case-control studies type. The search terms were "dry needling" or "trigger point dry needling" or "myofascial trigger point dry needling" and "plantar fasciitis" or "plantar fasciopathy" or "heel pain" or "plantar heel pain" or "plantar fascia" or "plantar fascia" or "heel spur". The PubMed, Google Scholar, Science Direct databases were searched up to 2017.

The methodological quality of the studies was rated with the (Physiotherapy Evidence-based Database) PEDro scale. According to the PEDro scale, the articles are classified into three qualities, high quality (6-10.10), fair quality (4-5.10) and poor quality $(\leq 3.10)$.

\section{Results}

\section{Dry needling in plantar heel pain and plantar fasciitis}

Seven studies were identified through the database that examined the effects of dry needling to treat people with plantar heel pain and PF [49-55].

\section{Description of included studies}

One study examined the effects of the platelet-rich plasma vs. dry needling of myofascial meridian trigger points in the treatment of PF. Thirty subjects with PF participated in the study. The subjects were divided randomly into two groups: One group received $3 \mathrm{ml}$ of the extracted Platelet-Rich Plasma (PRP) at the insertion of the plantar fascia, and other group received dry needling protocol once per week for six weeks in myofascial meridians trigger points along the superficial backline. The clinical assessment of foot function was done by the Foot Function Index (FFI), which is a 23 item scale. This study compared the baseline and after 6 and 12 weeks after the intervention with FFI and ultrasonography. Reem El Mallah et al. found a significant improvement in the clinical outcome of the FFI after 6 and 12 weeks in both groups. There was no significant difference between two groups at baseline and after 6 and 12 
weeks in plantar fascia thickness [52]. The PEDro scoring of the article was 5.10 (fair quality) (Table 1).

Another study evaluated the effectiveness of a four course of dry needling on chronic pain in subjects with PF. In this study, 20 subjects with PF were randomized to receive either one of two interventions; dry needling with a four week (one treatment per week) period combined with plantar muscles stretching or plantar muscles stretching alone. Furthermore, all patients received 50 mg diclofenac sodium per 12 hours and used an orthostatic plantar pad. Outcome measures include pain severity, range of motion of ankle dorsiflexion, and plantar flexion also Foot Function Index were assessed at baseline, and after four and eight weeks.

Significant improvements in plantar heel pain, as measured on a Visual Analog Scale, and ankle dorsiflexion were observed after four weeks of intervention and four weeks of withdrawal period regardless of treatment group. A comparison of the FFI revealed significant changes after four weeks of intervention in both groups four weeks after the intervention. Eftekharsadat et al. told that the mean VAS scores and FFI index in the dry needling group were significantly lower than the other group after four weeks of the intervention. There was no significant difference between two groups in ankle dorsiflexion and plantarflexion following four weeks of intervention [51]. The PEDro scoring of the article was 7.10 (high quality) (Table 1).

Another study evaluated the effectiveness of trigger point dry needling for plantar heel pain. A total of 84 patients with plantar heel pain participated in this study. The patients were randomized to be treated by dry needling or sham trigger point dry needling. The treatment consisted of one 30 minute session per week, over sixweeks. The outcome variables were first-step pain, as measured with a Visual Analog Scale (VAS), and foot pain, as measured with the pain subscale of the Foot Health Status Questionnaire (FHSQ). Primary outcome measures were assessed at baseline, and after 2, 4, 6, and 12 weeks. The secondary outcome measures in this study were foot function and general foot health, physical and mental health, the self-reported magnitude of symptom change, and foot posture. Their variables were evaluated at baseline, and then after 6 and 12 weeks.

The real dry needling group and sham group showed decreased pain at six weeks; however, there was significant difference between two groups. At 6 and 12 weeks, there were no significant differences between the two groups in secondary outcomes, including foot function, general foot health, and health-related quality of life [53]. The PEDro scoring of the article was 7.10 (high quality) (Table 1).

Akhbari et al. assessed the effectiveness of the use of dry needling based on myofascial meridians for the treatment of PF. A 53-year-old man with bilateral foot pain and $\mathrm{PF}$ participated in this study. There was tenderness on tender points along with the insertion of Achilles tendon, medial gastrocnemius, biceps femoris, semimembranosus, and ischial tuberosity. Dry needling based on myofascial meridians of the trigger points was used for four treatments over two weeks, and the subject returned to his full daily activities. Akhbari et al. showed the effectiveness of dry needling based on myofascial meridians for PF. They suggested that dry needling based on myofascial meridians could provide sign and symptom relief for cases with PF [50].

Perez-Millan et al. investigated the effectiveness of trigger point needling combined with electroacupuncture. Eleven patients with plantar heel pain participated in this study. Treatment includes trigger point dry needling plus electroacupuncture, which was administered one time a week for six weeks. This study did not have a control group. The outcome variables were severity pain, as measured with VAS, and Foot Function Index. All evaluations were performed before treatment and after the last treatment session (six weeks). A significant improvement was noted in pain severity between the pre- and post-intervention [49]. The PEDro scoring of the article was 3.10 (poor quality) (Table 1).

Tillu and Gupta investigated the effectiveness of four week period acupuncture on PF. If complete pain reduction was not obtained after a four week course acupuncture treatment, the patients received a two week course of trigger point dry needling in gastro-soleus muscle and plantar fascia combined with acupuncture. A total of 18 individuals with PF were recruited for the study. This study did not have a control group. The outcome variables were pain severity and percentage improvement, as measured with verbal ranking. Outcome variables were assessed at baseline, and then after four and six weeks. Significant improvement in the reduction of pain scores was seen at four and six weeks after the intervention. There was a statistically significant reduction in the VAS obtained at six weeks (after acupuncture treatment plus trigger point dry needling) compared to that obtained after the first four weeks of acupuncture treatment. It was noted that the verbal pain score improved after four and six weeks intervention [54]. The PEDro scoring of the article was 2.10 (poor quality), as shown in Table 1 . 
In another study, 29 patients with a clinical diagnosis of PF were assigned into the case group $(n=20)$ and control group $(n=9)$. The treatment group received dry needling and infiltration $1 \%$ lidocaine at the medial gastrocnemius and conventional conservative therapy. The control group received conventional conservative therapy only. Conventional therapy includes the use of hot packs, electrical stimulation and relaxation, and stretching exercises. The outcome measures will be pain severity (assessed using the VAS) and duration treatment and time to return to work. Outcome variables will be performed at baseline and after the intervention. Follow-up continued two years for case group. A significant improvement in the reduction in pain scores was seen in two groups. The comparison between the two groups revealed a significant decrease in the period of treatment and duration to return to work activity. Follow up showed that the improvement achieved in the case group was not short term [55]. The PEDro scoring of the article was 4.10 (fair quality) as shown in Table 1.

1. Eligibility criteria were specified; 2 . Subjects were randomly allocated to groups (in a crossover study, subjects were randomly allocated an order in which treatments were received; 3 . Allocation was concealed; 4. The groups were similar at baseline regarding the most important prognostic indicators; 5. There was blinding of all; 6 . There was blinding of all therapists who administered the therapy; 7. There was blinding of all assessors who measured at least one key outcome; 8. Measures of at least one key outcome were obtained from more than $85 \%$ of the subjects initially allocated to groups; 9 . All subjects for whom outcome measures were available received the treatment or control condition as allocated or, where this was not the case, data for at least one key outcome was analyzed by "intention to treat"; 10 . The results of between-group statistical comparisons are re- ported for at least one key outcome; and 11. The study provides both point measures and measures of variability for at least one key outcome (Table 1)

Total score: According to the PEDro scale, the articles are classified into three qualities, high quality (6-10.10), fair quality (4-5.10) and poor quality $(\leq 3.10)$ (Table 1$)$.

\section{Discussion}

In this review study, we considered all the articles comparing dry needling therapy with placebo, conventional treatment, and other treatments in individuals with plantar fasciitis and plantar heel pain. Seven articles were included in this review [50-54]. The PEDro scale was used to measure methodological quality. The PEDro scoring of the articles ranged between 2.10 and 7.10. Of the studies included, two articles had a high-quality study $[51,53]$. Of the seven articles that met our inclusion criteria, one article had placebo control group [53]. Two articles lacked a control group for comparison outcomes [49, 54]. Two articles evaluated the effectiveness of combined treatment (acupuncture treatment plus trigger point dry needling) [49, 54]. Of the studies selected, Imunura et al. had two years follow up [55]. There was diversity in the protocol of dry needling therapy in the selected articles. There was variability in the outcome measurement tools used to evaluate patients with plantar heel pain and plantar fasciitis in seven articles.

Many types of well-established conservative treatments are available for plantar heel pain, such as therapeutic exercise, foot and ankle mobilization, electrical stimulation for pain reduction, taping, footwear modification, orthotics, extracorporeal shock wave therapy, and laser therapy [41-43, 46-48].

Table 1. The PEDro scale

\begin{tabular}{|c|c|c|c|c|c|c|c|c|c|c|c|c|}
\hline \multirow{2}{*}{ PEDro Scale Items } & \multicolumn{11}{|c|}{ Items } & \multirow{2}{*}{ Total Score } \\
\hline & 1 & 2 & 3 & 4 & 5 & 6 & 7 & 8 & 9 & 10 & 11 & \\
\hline Reem El Mallah et al. [53] & + & - & - & + & - & - & - & + & + & + & + & 5.10 \\
\hline Eftekharsadat et al. [52] & + & + & - & + & + & - & - & + & + & + & + & 7.10 \\
\hline Cotchett MP et al. [54] & + & + & - & + & + & - & - & + & + & + & + & 7.10 \\
\hline Perez-Millan et al. [50] & - & - & - & - & - & - & - & + & + & - & + & 3.10 \\
\hline Tillu and Gupta [55] & - & - & - & - & - & - & - & + & + & - & - & 2.10 \\
\hline Imamura et al. [56] & + & - & - & - & - & - & - & + & + & + & + & 4.10 \\
\hline
\end{tabular}

${ }^{+}$Criterion was satisfied; - Criterion was not satisfied 
Trigger point dry needling is a treatment modality commonly used by physiotherapists for the management of individuals with musculoskeletal disorders such as plantar heel pain. There are several published studies that have investigated the effectiveness of trigger point needling in improving pain and function in musculoskeletal pain syndromes $[56,59,60,67,68]$. A systematic review evaluated the effectiveness of dry needling for upperquarter myofascial pain. This study reported that dry needling had a more significant effect on pain, compared to sham or placebo treatment [67].

A systematic review found that trigger point dry needling appears to be an effective treatment intervention for the improvement of trigger point-associated pain at various region body [69]. A systematic review provides strong evidence for the effectiveness of dry needling in the improvement of trigger point-associated pain in the lower extremity. According to this study, dry needling does not have a significant effect on limb function, level of activity, psychology, range of motion of joint and muscle strength and endurance [68]. Several studies have used dry needling for the treatment of tendinopathy [7073]. The findings suggest that dry needling does have a positive impact on tendon healing by improvement in blood flow, local vasodilation, collagen proliferation.

\section{Conclusion}

The results of this review indicate that dry needling may be useful in improving pain in individuals with plantar heel pain and PF. However, we need more highquality research studies to determine the effectiveness of dry needling in the management of plantar heel pain. Because a variety of protocol treatments of dry needling were used in the studies, recommendations about dry needling schedule prescriptions cannot be made for the management of individuals with plantar heel pain and plantar fasciitis.

\section{Ethical Considerations}

\section{Compliance with ethical guidelines}

All the procedures were carried out after the study was approved by the Scientific Board and Ethics Committee of the School of Rehabilitation, Tehran University of Medical Science. (Ethic Committee Code: IR.TUMS. VCR.REC.1397.231;2018/26/05).

\section{Funding}

The present paper was extracted from the $\mathrm{PhD}$. Thesis of the first author, Saman Salehi, Department of Physiotherapy, School of Rehabilitation, Tehran University of Medical Sciences.

\section{Authors contributions}

Carrying out the literature search and review, conceptualization, methodology, reading and approving the final article: All authors; Search strategy: Saman Salehi, Azadeh Shadmehr; Preparing the initial draft: Saman Salehi; Preparing the manuscript revisions: Azadeh Shadmehr, Gholamreza Olyaei, Siamak Bashardoust Tajali, Seyed Mohsen Mir.

\section{Conflict of interest}

The authors declare that they have no conflicts of interest.

\section{Acknowledgements}

The authors would like to appreciate the assistance of the Faculty members and the staff of the Tehran University of Medical Sciences, School of Rehabilitation.

\section{References}

[1] Roxas M. Plantar fasciitis: Diagnosis and therapeutic considerations. Alternative Medicine Review: A Journal of Clinical Therapeutic. 2005; 10(2):83-93. [PMID]

[2] Irving DB, Cook JL, Young MA, Menz HB. Obesity and pronated foot type may increase the risk of chronic plantar heel pain: A matched case-control study. BMC Musculoskeletal Disorders. 2007; 8:41. [DOI:10.1186/1471-2474-8-41] [PMID] [PMCID]

[3] Thomas MJ, Roddy E, Zhang W, Menz HB, Hannan MT, Peat GM. The population prevalence of foot and ankle pain in middle and old age: A systematic review. Pain. 2011; 152(12):2870-80. [DOI:10.1016/j.pain.2011.09.019] [PMID]

[4] Riddle DL, Pulisic M, Sparrow K. Impact of demographic and impairment-related variables on disability associated with plantar fasciitis. Journal of Foot and Ankle Research. 2004; 25(5):311-7. [DOI:10.1177/107110070402500506] [PMID]

[5] Crawford F. Plantar heel pain and fasciitis. Clinical Evidence Journal. 2004; 2004(11):1589-602. [PMID]

[6] Werner RA, Gell N, Hartigan A, Wiggerman N, Keyserling WM. Risk factors for plantar fasciitis among assembly plant workers. PM \& R: The Journal of Injury, Function, and Rehabilitation. 2010; 2(2):110-6. [DOI:10.1016/j.pmrj.2009.11.012] [PMID] 
[7] Scher DL, Belmont PJJr, Bear R, Mountcastle SB, Orr JD, Owens BD. The incidence of plantar fasciitis in the United States military. The Journal of Bone and Joint Surgery. 2009; 91(12):2867-72. [DOI:10.2106/JBJS.I.00257] [PMID]

[8] Sweeting D, Parish B, Hooper L, Chester R. The effectiveness of manual stretching in the treatment of plantar heel pain: A systematic review. Journal of Foot and Ankle Research. 2011; 4(1):19. [DOI:10.1186/1757-1146-4-19] [PMID] [PMCID]

[9] Barrett SJ, O'Malley R. Plantar fasciitis and other causes of heel pain. American Family Physician. 1999; 59(8):2200-6. [PMID]

[10] Lysholm J, Wiklander J. Injuries in runners. The American Journal of Sports Medicine. 1987; 15(2):168-71. [DOI:10.1177/ 036354658701500213] [PMID]

[11] Wearing SC, Smeathers JE, Urry SR, Hennig EM, Hills AP. The pathomechanics of plantar fasciitis. Sports Medicine. 2006; 36(7):585-611. [DOI:10.2165/00007256-200636070-00004] [PMID]

[12] Rompe JD. Plantar fasciopathy. Sports Medicine and Arthroscopy Review. 2009; 17(2):100-4. [DOI:10.1097/ JSA.0b013e3181a3d60e] [PMID]

[13] Lemont H, Ammirati KM, Usen N. Plantar fasciitis: A degenerative process (fasciosis) without inflammation. Journal of the American Podiatric Medical Association. 2003; 93(3):234-7. [DOI:10.7547/87507315-93-3-234] [PMID]

[14] Thomas JL, Christensen JC, Kravitz SR, Mendicino RW, Schuberth JM, Vanore JV, et al. The diagnosis and treatment of heel pain: A clinical practice guideline-revision 2010. The Journal of Foot and Ankle Surgery. 2010; 49(Suppl. 3):S1-19. [DOI:10.1053/j.jfas.2010.01.001] [PMID]

[15] Radwan A, Wyland M, Applequist L, Bolowsky E, Klingensmith $\mathrm{H}$, Virag I. Ultrasonography, an effective tool in diagnosing plantar fasciitis: A systematic review of diagnostic trials. International Journal of Sports Physical Therapy. 2016; 11(5):663-71. [PMID] [PMCID]

[16] Riel H, Cotchett M, Delahunt E, Rathleff MS, Vicenzino B, Weir A, et al. Is 'plantar heel pain'a more appropriate term than 'plantar fasciitis'? Time to move on. British Journal of Sports Medicine. 2017; 51(22):1576-7. [DOI:10.1136/bjsports-2017-097519] [PMID]

[17] Fraser JJ, Glaviano NR, Hertel J. Utilization of physical therapy intervention among patients with plantar fasciitis in the United States. The Journal of Orthopaedic and Sports Physical Therapy. 2017; 47(2):49-55. [DOI:10.2519/Journal of Orthopaedic \& Sports Physical Therapy.2017.6999] [PMID]

[18] McPoil TG, Martin RL, Cornwall MW, Wukich DK, Irrgang JJ, Godges JJ. Heel pain-plantar fasciitis: clinical practice guildelines linked to the international classification of function, disability, and health from the orthopaedic section of the American Physical Therapy Association. The Journal of Orthopaedic and Sports Physical Therapy. 2008; 38(4):A1-18 [DOI:10.2519/Journal of Orthopaedic \& Sports Physical Therapy.2008.0302] [PMID]

[19] Klein SE, Dale AM, Hayes MH, Johnson JE, McCormick JJ, Racette BA. Clinical presentation and self-reported patterns of pain and function in patients with plantar heel pain. Foot \& Ankle International. 2012; 33(9):693-8. [DOI:10.3113/ FAI.2012.0693] [PMID] [PMCID]
[20] Riddle DL, Pulisic M, Pidcoe P, Johnson RE. Risk factors for plantar fasciitis: A matched case-control study. The Journal of Bone and Joint Surgery, American Volume. 2003; 85(5):872-7. [DOI:10.2106/00004623-200305000-00015] [PMID]

[21] Irving DB, Cook JL, Young MA, Menz HB. Impact of chronic plantar heel pain on health-related quality of life. Journal of the American Podiatric Medical Association. 2008; 98(4):283-9. [DOI:10.7547/0980283] [PMID]

[22] Draghi F, Gitto S, Bortolotto C, Draghi AG, Belometti GO. Imaging of plantar fascia disorders: Findings on plain radiography, ultrasound and magnetic resonance imaging. Insights Imaging. 2017; 8(1):69-78. [DOI:10.1007/s13244-016-0533-2] [PMID] [PMCID]

[23] Van Leeuwen KD, Rogers J, Winzenberg T, van Middelkoop M. Higher body mass index is associated with plantar fasciopathy/'plantar fasciitis': Systematic review and meta-analysis of various clinical and imaging risk factors. British Journal of Sports Medicine. 2016; 50(16):972-81. [DOI:10.1136/ bjsports-2015-094695] [PMID]

[24] Huang YC, Wang LY, Wang HC, Chang KL, Leong CP. The relationship between the flexible flatfoot and plantar fasciitis: Ultrasonographic evaluation. Chang Gung Medical Journal. 2004; 27(6):443-8. [PMID]

[25] Abdel-wahab N, Fathi S, AL-emadi S, Mahdi S. High-resolution ultrasonographic diagnosis of plantar fasciitis: A correlation of ultrasound and magnetic resonance imaging. International Journal of Rheumatic Diseases. 2008; 11(3):279-86. [DOI:10.1111/j.1756-185X.2008.00363.x]

[26] Akfirat M, Sen C, Günes T. Ultrasonographic appearance of the plantar fasciitis. Clinical Imaging. 2003; 27(5):353-7. [DOI:10.1016/S0899-7071(02)00591-0]

[27] Dutton M. Dutton's orthopaedic: Examination, evaluation and intervention. New York: McGraw Hill Professional; 2016.

[28] Young CC, Rutherford DS, Niedfeldt MW. Treatment of plantar fasciitis. American Family Physician. 2001; 63(3):46774. [PMID]

[29] Alvarez-Nemegyei J, Canoso JJ. Heel pain: Diagnosis and treatment, step by step. Cleveland Clinic Journal of Medicine. 2006; 73(5):465-71. [DOI:10.3949/ccjm.73.5.465] [PMID]

[30] Goff JD, Crawford R. Diagnosis and treatment of plantar fasciitis. American Family Physician. 2011; 84(6):676-82. [PMID]

[31] Abul K, Ozer D, Sakizlioglu SS, Buyuk AF, Kaygusuz MA. Detection of normal plantar fascia thickness in adults via the ultrasonographic method. Journal of the American Podiatric Medical Association. 2015; 105(1):8-13. [DOI:10.7547/87507315-105.1.8] [PMID]

[32] Cheng JW, Tsai WC, Yu TY, Huang KY. Reproducibility of sonographic measurement of thickness and echogenicity of the plantar fascia. Journal of Clinical Ultrasound. 2012 40(1):14-9. [DOI:10.1002/jcu.20903] [PMID]

[33] Theodorou DJ, Theodorou SJ, Resnick D. MR imaging of abnormalities of the plantar fascia. Semin Musculoskelet Radiol. 2002; 6(2):105-18. [DOI:10.1055/s-2002-32357] [PMID]

[34] Jeswani T, Morlese J, McNally EG. Getting to the heel of the problem: Plantar fascia lesions. Clinical Radiology. 2009; 64(9):931-9. [DOI:10.1016/j.crad.2009.02.020] [PMID] 
[35] McNally EG, Shetty S. Plantar fascia: Imaging diagnosis and guided treatment. Seminars in Musculoskeletal Radiology. 2010; 14(3):334-43. [DOI:10.1055/s-0030-1254522] [PMID]

[36] De Garceau D, Dean D, Requejo SM, Thordarson DB. The association between diagnosis of plantar fasciitis and Windlass test results. Foot \& Ankle International. 2003; 24(3):251-5. [DOI:10.1177/107110070302400309] [PMID]

[37] Pawar PA, Tople RU, Yeole UL, Gharote GM, Panse RB, Kulkarni SA. A study on effect of strain-counterstrain in plantar fasciitis. International Journal For The Advancement Medicine. 2017; 4(2):551-5. [DOI:10.18203/2349-3933. ijam20171059]

[38] Stecco C, Corradin M, Macchi V, Morra A, Porzionato A, Biz C, et al. Plantar fascia anatomy and its relationship with achilles tendon and paratenon. Journal of Anatomy. 2013; 223(6):665-76. [DOI:10.1111/joa.12111] [PMID] [PMCID]

[39] Othman AM, Ragab EM. Endoscopic plantar fasciotomy versus extracorporeal shock wave therapy for treatment of chronic plantar fasciitis. Archives of Orthopaedic and Traumatic Surgery. 2010; 130(11):1343-7. [DOI:10.1007/s00402009-1034-2] [PMID] [PMCID]

[40] Ehrmann C, Maier M, Mengiardi B, Pfirrmann CW, Sutter R. Calcaneal attachment of the plantar fascia: MR findings in asymptomatic volunteers. Radiology. 2014; 272(3):807-14. [DOI:10.1148/radiol.14131410] [PMID]

[41] Orchard J. Plantar fasciitis. The BMJ. 2012; 345:e6603. [DOI:10.1136/bmj.e6603] [PMID]

[42] Martin RL, Davenport TE, Reischl SF, McPoil TG, Matheson JW, Wukich DK, et al. Heel pain-plantar fasciitis: Revision 2014. Journal of Orthopaedic \& Sports Physical Therapy. 2014; 44(11):A1-A33. [DOI:10.2519/Journal of Orthopaedic \& Sports Physical Therapy.2014.0303] [PMID]

[43] Rosenbaum AJ, DiPreta JA, Misener D. Plantar heel pain. Medical Clinics. 2014; 98(2):339-52. [DOI:10.1016/j. mona.2013.10.009] [PMID]

[44] Rompe JD, Furia J, Weil L, Maffulli N. Shock wave therapy for chronic plantar fasciopathy. British Medical Bulletin. 2007; 81(1):183-208. [DOI:10.1093/bmb/ldm005] [PMID]

[45] Martin RL, Irrgang JJ, Conti SF. Outcome study of subjects with insertional plantar fasciitis. Foot \& Ankle International. 1998; 19(12):803-11. [DOI:10.1177/10711007980190120 3] [PMID]

[46] Macias DM, Coughlin MJ, Zang K, Stevens FR, Jastifer JR, Doty JF. Low-level laser therapy at $635 \mathrm{~nm}$ for treatment of chronic plantar fasciitis: a placebo-controlled, randomized study. The Journal of Foot and Ankle Surgery. 2015; 54(5):768-72. [DOI:10.1053/j.jfas.2014.12.014] [PMID]

[47] Jastifer JR, Catena F, Doty JF, Stevens F, Coughlin MJ. Lowlevel laser therapy for the treatment of chronic plantar fasciitis: A prospective study. Journal of Foot and Ankle Research. 2014; 35(6):566-71. [DOI:10.1177/1071100714523275] [PMID]

[48] Sun J, Gao F, Wang Y, Sun W, Jiang B, Li Z. Extracorporeal shock wave therapy is effective in treating chronic plantar fasciitis: A meta-analysis of RCTs. Medicine. 2017; 96(15):e6621. [DOI:10.1097/MD.0000000000006621] [PMID] [PMCID]
[49] Perez-Millan R, Foster L. Low frequency electroacupuncture in the management of refractory plantar fasciitis. Medicine Acupunct. 2001; 13(1):1-6.

[50] Behnam A, Mahyar S, Ezzati K, Rad SM. The use of dry needling and myofascial meridians in a case of plantar fasciitis. Journal of Chiropractic Medicine. 2014; 13(1):43-8. [DOI:10.1016/j.jcm.2014.01.006] [PMID] [PMCID]

[51] Eftekharsadat B, Babaei-Ghazani A, Zeinolabedinzadeh V Dry needling in patients with chronic heel pain due to plantar fasciitis: A single-blinded randomized clinical trial. Medical Journal of the Islamic Republic of Iran. 2016; 30:401.

[52] El Mallah R, Elattar EA, Zidan HF. Platelet-rich plasma versus dry needling of myofascial meridian trigger points in the treatment of plantar fasciitis. Egyptian Rheumatology and Rehabilitation. 2017; 44(2):58. [DOI:10.4103/1110-161X.205661]

[53] Cotchett MP, Munteanu SE, Landorf KB. Effectiveness of trigger point dry needling for plantar heel pain: A randomized controlled trial. Physical Therapy. 2014; 94(8):1083-94. [DOI:10.2522/ptj.20130255] [PMID]

[54] Tillu A, Gupta S. Effect of acupuncture treatment on heel pain due to plantar fasciitis. Acupuncture in Medicine. 1998; 16(2):66-8. [DOI:10.1136/aim.16.2.66]

[55] Imamura M FA, Imamura ST, Kaziyama HS, Carvalho AE, Salomao O Journal of musculoskeletal pain. Treatment of myofascial pain components in plantar fasciitis speeds up recovery: Documentation by algometry. Journal of Musculoskeletal Pain. 1998; 6(1):91-100. [DOI:10.1300/J094v06n01_07]

[56] Dommerholt J, Huijbregts P. Myofascial trigger points: pathophysiology and evidence-informed diagnosis and management. Burlington: Jones \& Bartlett Learning; 2010.

[57] Association APT. Description of dry needling in clinical practice: An educational resource paper. Alexandria: American Physical Therapy Association. 2013.

[58] Dommerholt J, Mayoral del Moral O, Gröbli C. Trigger point dry needling. Journal of Manual \& Manipulative Therapy. 2006; 14(4):70E-87E. [DOI:10.1179/jmt.2006.14.4.70E]

[59] Lewit K. The needle effect in the relief of myofascial pain. Pain. 1979; 6(1):83-90. [DOI:10.1016/0304-3959(79)90142-8]

[60] Casanueva B, Rivas P, Rodero B, Quintial C, Llorca J, González-Gay MA. Short-term improvement following dry needle stimulation of tender points in fibromyalgia. Rheumatology International. 2014; 34(6):861-6. [DOI:10.1007/s00296013-2759-3] [PMID]

[61] Simons DG, Travell JG, Simons LS. Travell \& Simons' myofascial pain and dysfunction: Upper half of body. Philadelphia: Lippincott Williams \& Wilkins; 1999.

[62] Baldry P, Yunus MB, Inanici F. Myofascial pain and fibromyalgia syndromes: A clinical guide to diagnosis and management. London: Elsevier Health Sciences; 2001.

[63] Shah JP, Danoff JV, Desai MJ, Parikh S, Nakamura LY, Phillips TM, et al. Biochemicals associated with pain and inflammation are elevated in sites near to and remote from active myofascial trigger points. Archives of Physical Medicine and Rehabilitation. 2008; 89(1):16-23. [DOI:10.1016/j. apmr.2007.10.018] [PMID] 
[64] Shah JP, Phillips TM, Danoff JV, Gerber LH. An in vivo microanalytical technique for measuring the local biochemical milieu of human skeletal muscle. Canadian Journal Of Applied Physiology. 2005; 99(5):1977-84. [DOI:10.1152/japplphysiol.00419.2005] [PMID]

[65] Melzack R. Myofascial trigger points: Relation to acupuncture and mechanisms of pain. Archives of Physical Medicine and Rehabilitation. 1981; 62(3):114-7.

[66] Furlan AD, van Tulder M, Cherkin D, Tsukayama $\mathrm{H}$ Lao L, Koes B, et al. Acupuncture and dry-needling for low back pain: an updated systematic review within the framework of the cochrane collaboration. Spine. 2005; 30(8):944-63. [DOI:10.1097/01.brs.0000158941.21571.01] [PMID]

[67] Kietrys DM, Palombaro KM, Azzaretto E, Hubler R, Schaller B, Schlussel JM, et al. Effectiveness of dry needling for upper-quarter myofascial pain: A systematic review and meta-analysis. The Journal of Orthopaedic and Sports Physical Therapy. 2013; 43(9):620-34. [DOI:10.2519/Journal of Orthopaedic \& Sports Physical Therapy.2013.4668] [PMID]

[68] Morihisa R, Eskew J, McNamara A, Young J. Dry needling in subjects with muscular trigger points in the lower quarter: A systematic review. International Journal of Sports Physical Therapy. 2016; 11(1):1-14.

[69] Boyles R, Fowler R, Ramsey D, Burrows E. Effectiveness of trigger point dry needling for multiple body regions: A systematic review. The Journal of Manual \& Manipulative Therapy. 2015; 23(5):276-93. [DOI:10.1179/204261861 5Y.0000000014] [PMID] [PMCID]

[70] Sandberg M, Lundeberg T, Lindberg LG, Gerdle B. Effects of acupuncture on skin and muscle blood flow in healthy subjects. European Journal of Applied Physiology and Occupational Physiology. 2003; 90(1-2):114-9. [DOI:10.1007/s00421003-0825-3] [PMID]

[71] James SL, Ali K, Pocock C, Robertson C, Walter J, Bell J, et al. Ultrasound guided dry needling and autologous blood injection for patellar tendinosis. British Journal of Sports Medicine. 2007; 41(8):518-21 [DOI:10.1136/bjsm.2006.034686] [PMID] [PMCID]

[72] Neal BS, Longbottom J. Is there a role for acupuncture in the treatment of tendinopathy? Acupuncture in Medicine. Acupuncture in Medicine. 2012; 30(4):346-9. [DOI:10.1136/ acupmed-2012-010208] [PMID]

[73] Langevin HM, Bouffard NA, Churchill DL, Badger GJ Connective tissue fibroblast response to acupuncture: Dosedependent effect of bidirectional needle rotation. Journal of Alternative and Complementary (New York). 2007; 13(3):355-60. [DOI:10.1089/acm.2007.6351] [PMID] [PMCID] 
This Page Intentionally Left Blank 